\title{
On Cyclic Variability in a Residual Effected HCCI Engine with Direct Gasoline Injection during Negative Valve Overlap
}

\author{
Jacek Hunicz \\ Faculty of Mechanical Engineering, Lublin University of Technology, Nadbystrzycka 36, 20-618 Lublin, Poland \\ Correspondence should be addressed to Jacek Hunicz; j.hunicz@pollub.pl
}

Received 4 August 2014; Accepted 9 December 2014; Published 25 December 2014

Academic Editor: Grzegorz Litak

Copyright ( 2014 Jacek Hunicz. This is an open access article distributed under the Creative Commons Attribution License, which permits unrestricted use, distribution, and reproduction in any medium, provided the original work is properly cited.

\begin{abstract}
This study contributes towards describing the nature of cycle-by-cycle variability in homogeneous charge compression ignition (HCCI) engines. Experimental measurements were performed using a single cylinder research engine operated in the negative valve overlap (NVO) mode and fuelled with direct gasoline injection. Both stoichiometric and lean mixtures were applied in order to distinguish between different exhaust-fuel reactions during the NVO period and their propagation into the main event combustion. The experimental results show that the mode of cycle-by-cycle variability depends on the NVO phenomena. Under stoichiometric mixture conditions, neither variability in the main event indicated mean effective pressure (IMEP) nor the combustion timing was affected by the NVO phenomena; however, long period oscillations in IMEP were observed. In contrast, for lean mixture, where fuel oxidation during the NVO period took place, distinctive correlations between NVO phenomena and the main event combustion parameters were observed. A wavelet analysis revealed the presence of both long-term and short-term oscillations in IMEP, in accordance with the extent of NVO phenomena. Characteristic patterns in IMEP were recognized using an in-house algorithm.
\end{abstract}

\section{Introduction}

Each combustion engine exhibits a certain cycle-by-cycle variability even if it is operated under steady conditions [1]. The cyclic instability can be observed in the variations of incylinder pressure traces between particular cycles, especially during combustion. The amount of work produced by individual engine cycles is variable as well, which results in torque fluctuations and deterioration of engine efficiency [2]. Cycleby-cycle fluctuations are usually identified as combustion variations in terms of peak pressure, maximum heat release rate, the amount of heat released, and combustion timing. The remaining in-cylinder parameters, such as in-cylinder fluid motion, the amount of recirculated exhaust, and fuel distribution within the cylinder, are widely recognized as causes of operation roughness [2,3]. Also, high discrepancies between combustion processes in individual cylinders are typical of multicylinder engines [4].

Low temperature combustion in homogeneous charge compression ignition (HCCI) engines is an emerging combustion technique that offers unique benefits over existing combustion systems. Uniform in-cylinder temperature and a high degree of mixture dilution enable a substantial reduction in nitrogen oxides emission. Additionally, spontaneous combustion of the whole in-cylinder volume results in high thermal efficiency $[5,6]$. The most feasible approach to HCCI combustion is the utilization of negative valve overlap (NVO) that results in exhaust gas trapping. This enables autoignition of gasoline-like fuels under relatively low compression ratios, typical of spark ignition engines. Retained residuals increase the in-cylinder temperature to the level enabling autoignition of the in-cylinder mixture at the end of compression $[7,8]$. Considering specific principles of residual effected HCCI engine utilizing NVO, the approach to the cyclic variability should be verified as well. Trapped residuals are the carrier between consecutive combustion cycles [9-11]. Furthermore, due to the limited time for mixing trapped residuals with fresh air, the in-cylinder mixture is not perfectly homogeneous [12] and, consequently, uneven in the cyclic domain. If fuel is injected during the NVO period, fuel-exhaust reactions introduce further complexities into cycle-by-cycle couplings [13]. The extent of processes influencing the course of combustion and the feedback-loop between consecutive cycles 
makes the cycle-by-cycle variability a complex and highdimensional process.

During the last decade, a lot of effort has been put into understanding the mechanisms of cyclic variability in HCCI engines. Koopmans et al. [9] described cycle-by-cycle variability of combustion timing in an engine with direct $\mathrm{NVO}$ injection. They observed self-excited oscillations of $50 \%$ mass fraction burned (MFB) damped after a couple of cycles. Fast exhaust port temperature measurements revealed the lack of correlation between exhaust temperature and combustion timing. However, it was found that late combustion cycles produced high content of unburned hydrocarbons. Since not all fuel was consumed during the main event, more oxygen was available during the subsequent NVO period, which enhanced NVO heat release. The latter process increased the in-cylinder temperature, which had an advancing effect on the combustion timing. The authors hypothesized that the oscillations resulted from variations in the excess air ratio and dilution rate. The present author's previous work [14] demonstrated that, under lightly boosted operation and for a lean mixture, periodic oscillations of autoignition timing did not disappear. It is plausible that the damping of oscillations is associated with the thermal balance of the intake process. Under forced air induction conditions, where the self-regulation process was corrupted, stabilization was not observed.

Wagner et al. [15] and Daw et al. [16] demonstrated deterministic patterns with regard to cyclic variations of cumulative heat release in HCCI engines and developed a statistical model for the prediction of heat release on the basis of time series data. The authors hypothesized that cyclic variations result mainly from nonlinear internal exhaust gas recirculation (EGR) feedback. Correlations between consecutive engine cycles were also studied by Hellström et al. [11], who found that the subsequent cycles were coupled by feedback from incomplete combustion. Ghazimirsaied and Koch [17] developed an algorithm enabling the prediction of combustion timing one cycle ahead on the basis of the peak pressure crank angles from two previous cycles. They also demonstrated peak pressure patterns at engine operation close to the misfire limit.

The purpose of the present study was to explore cycle-bycycle variability in an HCCI engine under different exhaustfuel reactions. The engine was operated in the NVO mode and fuel was injected into the cylinder during exhaust recompression. In order to account for the variable nature of NVO exhaust-fuel reactions, the engine was operated under stoichiometric and lean mixture regime. The cycle-by-cycle phenomena were analyzed on the basis of work produced by a single engine cycle and combustion timing. Wavelet analyses were applied in order to identify nonstationary periodic components of cyclic variability. Furthermore, characteristic patterns of cyclic variability were isolated and demonstrated.

\section{Experimental Apparatus and Method}

2.1. Research Engine and Measurement Instrumentation. A single cylinder research engine was installed on a test bed equipped with a direct current dynamometer. The test stand

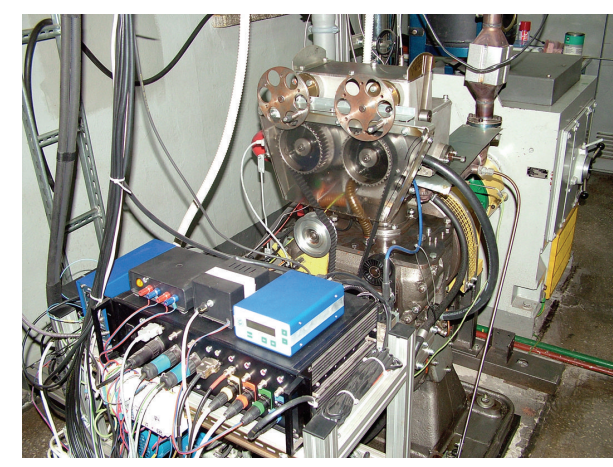

Figure 1: Test stand used in the experiments.

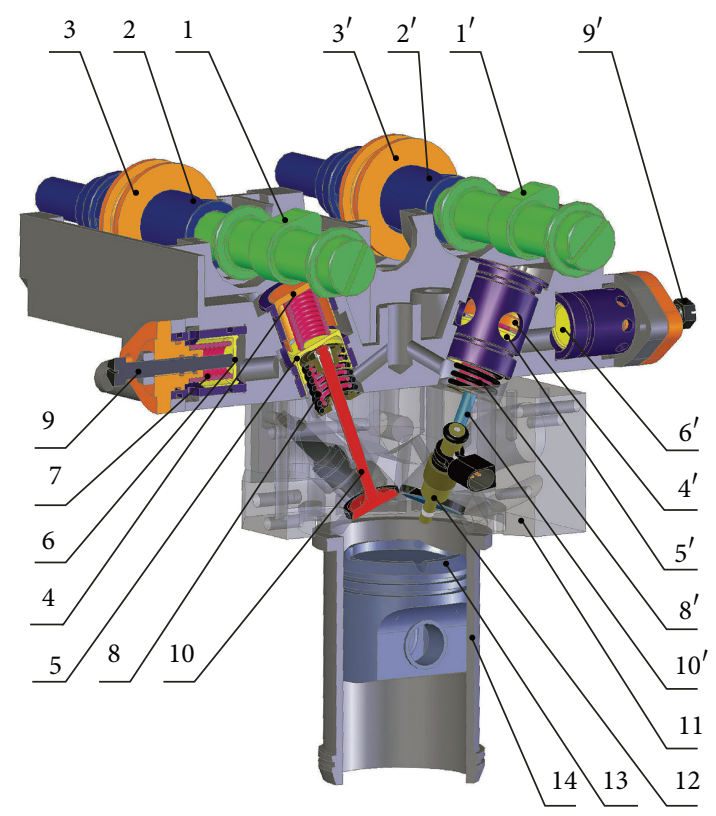

FIgURE 2: Cross-section of engine head and cylinder; 1-camshaft, 2-drive shaft, 3-sliding sleeve, 4-cam piston, 5-valve piston, 6piston of hydraulic accumulator, 7-spring of hydraulic accumulator, 8-valve springs, 9-valve lift regulating screw, 10-valve, 11engine head, 12-fuel injector, 13-piston, and 14-cylinder liner.

is shown in Figure 1. The engine was equipped with a mechanical variable valvetrain to enable the control of valve lifts and timings. The cams provided maximum valve lifts of $9.4 \mathrm{~mm}$ and valve opening durations of $235^{\circ} \mathrm{CA}$. The valve lifts were adjusted using the hydraulic mechanism shown in Figure 2. The operation procedure of the valvetrain was as follows. The cam (1) actuated the piston (4), while the valve was actuated by the piston (5). The clearance between the pistons (4) and (5) was filled with oil and connected with the hydraulic accumulator clearance volume. The motion of the hydraulic accumulator piston (6) was limited by the regulation screw (9). The variable of the hydraulic accumulator clearance volume changed idle stroke of the cam piston (4), thus reducing the active part of the cam lift. The effect of reduction of valve lifts was similar to the effect which could be achieved by increasing the clearance between the cam and the valve tappet. 
TABLE 1: Single cylinder research engine specifications.

\begin{tabular}{lc}
\hline Displaced volume & $498.5 \mathrm{~cm}^{3}$ \\
Cylinder diameter & $84 \mathrm{~mm}$ \\
Piston stroke & $90 \mathrm{~mm}$ \\
Compression ratio & 11.7 \\
Number of valves & 2 \\
Fuel injector & Solenoid actuated swirl-type \\
Fuel-rail pressure & $11 \mathrm{MPa}$ max. \\
\hline
\end{tabular}

Thus, this mechanism varied both the valve lift and opening duration. Additionally, the valvetrain was equipped with mechanical timing adjusters, which enabled rotation of the camshaft sprockets in relation to camshafts $(1)$ and $\left(1^{\prime}\right)$.

The research engine had a bowl-shaped combustion chamber located in the engine head. The piston face was protruding on its perimeter and it approached the cylinder head closely at TDC, as shown in Figure 2, which generated a certain amount of squish. Fuel was applied to the cylinder using a side-mounted single-stream swirl-type injector. The main parameters of the engine are specified in Table 1.

The engine control system was based on in-house PC software connected with a real-time timing module which governed not only injection timings and durations, but also spark generation. However, spark discharge was switched off in the experiments and was used exclusively for the introduction of the engine into the HCCI mode.

The engine test bench was equipped with all necessary measurement and control instruments. Fuel consumption was measured using a fuel balance and intake airflow was measured with a thermal mass flow meter. The engine was also equipped with a set of pressure and temperature transducers in order to control the thermodynamic conditions of all media, intake, exhaust, cooling liquid, and so forth. Incylinder pressure was measured with the use of a miniature pressure transducer that was installed directly in the engine head. The pressure and other crank angle (CA) based parameters were recorded with a constant angular resolution of $0.1^{\circ} \mathrm{CA}$. At each operating condition, the in-cylinder pressure signal was recorded for 1000 consecutive cycles.

\subsection{Experimental Conditions and Procedure. The engine was} fuelled with pump-grade European commercial gasoline from a single batch. The experiments were conducted at a constant crankshaft rotational speed of $1500 \mathrm{rev} / \mathrm{min}$. The cooling liquid temperature at the engine outlet was maintained at $90^{\circ} \mathrm{C} \pm 1$. The engine was naturally aspirated and the intake air temperature was approximately $40^{\circ} \mathrm{C}$. The valvetrain was strategically set to achieve negative valve overlap and internal EGR. Fuel was introduced into the cylinder during the exhaust recompression in order to enable fuel reforming. Valvetrain settings and injection timing are shown in Figure 3. The reduction of valve opening crank angles using standard cams was associated with a simultaneous reduction of valve lifts, which resulted in valve lifts of $3.6 \mathrm{~mm}$ for the intake valve and $2.9 \mathrm{~mm}$ for the exhaust valve.

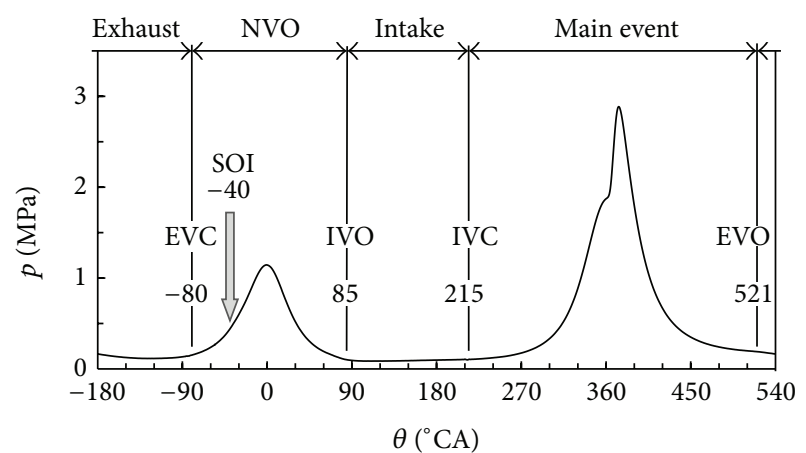

FIGURE 3: Engine operating cycle with a depiction of valve timings and injection timing.

A variable excess air ratio $(\lambda)$ was accomplished as a control variable in order to determine the effects of different NVO phenomena on combustion. The experiments were performed at stoichiometric mixture and at lean mixture, where $\lambda$ values were set to 1.1 and 1.2. The definition of excess air ratio is provided in the next subsection. Under stoichiometric conditions, where only a small amount of oxygen was present during NVO, exclusively endothermic reforming was expected. However, the average excess air ratio was maintained slightly lean in order to avoid rich mixture combustion and feedback from the $\mathrm{CO}$ content in the exhaust. At lean mixture, exothermic reactions resulting from oxidative reforming and/or partial combustion were expected to be the dominant phenomena. Thus, the performed analyses covered different NVO phenomena feedback on cycle-by-cycle variations in the main event.

2.3. Analysis of Experimental Data. The data analysis was performed with the use of in-house software, where the measured pressure traces were utilized as boundary conditions for zero-dimensional models of gas exchange and combustion. The aim of modeling was to provide cycle-by-cycle composition of in-cylinder fluid and, thus, a more detailed analysis of combustion evolution.

Gas flow rates through the intake valve and the exhaust valve were computed using formulas describing compressible fluid flow through the restriction [18]. For the intake process the following equations were used:

$$
\begin{aligned}
\dot{m}= & \frac{C_{\text {int }} A_{\text {int }} p_{\text {int }}}{\sqrt{R_{\text {int }} T_{\text {int }}}\left(\frac{p}{p_{\text {int }}}\right)^{1 / \gamma_{\text {int }}}} \\
& \times \sqrt{\frac{2 \gamma_{\text {int }}}{\gamma_{\text {int }}-1}\left[1-\left(\frac{p}{p_{\text {int }}}\right)^{\left(\gamma_{\text {int }}-1\right) / \gamma_{\text {int }}}\right]}
\end{aligned}
$$

when the flow was subcritical, and

$$
\dot{m}=\frac{C_{\text {int }} A_{\text {int }} p_{\text {int }}}{\sqrt{R_{\text {int }} T_{\text {int }}}} \sqrt{\gamma_{\text {int }}\left(\frac{2}{\gamma_{\text {int }}+1}\right)^{\left(\gamma_{\text {int }}+1\right) /\left(\gamma_{\text {int }}-1\right)}}
$$

when the flow was choked, that is, $\left(p / p_{\text {int }}\right) \leq\left(2 /\left(\gamma_{\text {int }}+\right.\right.$ $1))^{\gamma_{\text {int }} /\left(\gamma_{\text {int }}-1\right)}$. The intake valve curtain area $A_{\text {int }}$ was computed 
as a function of the valve lift and geometrical dimensions of both the valve and the valve seat. The discharge coefficient $C_{\text {int }}$ was measured experimentally as a function of the valve lift. For the intake process, the pressure upstream restriction was the intake runner pressure $p_{\text {int }}$ and pressure after restriction was the measured in-cylinder pressure $p$. The remaining thermodynamic parameters of the intake gas included the temperature $T_{\text {int }}$, the gas constant $R_{\text {int }}$, and the ratio of specific heats $\gamma_{\text {int }}$. The gas flow during the exhaust process was calculated in a similar manner, where the restriction upstream gas parameters were those inside the cylinder while the downstream parameters were measured in the exhaust runner. Obviously, the applied gas flow model accommodated backflow phenomena. The model also comprised a submodel of the intake runner; thus, effects of backflows on the mixture composition were taken into account.

The mass of the trapped residuals $m_{\text {exh }}$ was computed using the ideal gas equation of state based on the volume $V_{\mathrm{EVC}}$ and the pressure $p_{\mathrm{EVC}}$ at the exhaust valve closing (EVC) event and the exhaust temperature $T_{\text {exh }}$ using the following formula:

$$
m_{\mathrm{exh}}=\frac{p_{\mathrm{EVC}} V_{\mathrm{EVC}}}{R T_{\mathrm{exh}}} .
$$

The exhaust temperature was recorded by a thermocouple located in the exhaust port close to the valve.

The mass of the fuel injected in each cycle was computed using a simple injector model, where the mass flow rate was determined by the coil excitation duration $t_{\text {inj }}$ and the pressure difference between the fuel-rail and the cylinder. Hence, the mass of the fuel injected in $\mathrm{mg}$ was expressed as

$$
m_{F}=B_{\text {inj }}\left(t_{\text {inj }}-0.0179\right) \sqrt{p_{F}-p} .
$$

The flow model was tuned in by selection of the $B_{\text {inj }}$ parameter to provide a cumulative fuel flow rate for 1000 cycles, the same one as that measured by the fuel balance. The constant 0.0179 is the difference between the duration of coil excitation and the actual duration of injection in ms under given fuel pressure.

The mass averaged temperature inside the cylinder was computed using the gas equation of state:

$$
T=\frac{p V}{m R}
$$

where the in-cylinder mass $m$ consisted of the mass of aspirated air $m_{A}$, the mass of trapped residuals $m_{\text {exh }}$, and the mass of fuel $m_{F}$. Instantaneous values of the individual gas constant $R$ were computed according to the variable mixture composition inside the cylinder. The variable volume $V$ above the piston results from engine geometry and, as a function of the crankshaft position $\theta$, can be expressed as

$$
V(\theta)=\frac{V_{S}}{\mathrm{CR}-1}+\frac{\pi D^{2}}{4} r\left(1-\cos \theta+0.5 \frac{r}{l} \sin ^{2} \theta\right),
$$

where $\mathrm{CR}$ is the compression ratio, $D$ is the cylinder diameter, $r$ is the crank radius, and $l$ is the conrod length. More information on zero-dimensional engine modeling can be found in the studies [19-21].
The above model provided important in-cylinder parameters for each analyzed cycle separately, including cyclic fluctuations of mass and composition. It should be noted that the accuracy of computations is determined by the accuracy of in-cylinder pressure measurements. Thus, pressure transducer error would introduce bias to the estimated parameters. Nevertheless, this approach provided some insight into the cyclic variability of the in-cylinder mixture composition.

The indicated mean effective pressure (IMEP) was utilized to express the combustion system ability to do work. This measure is independent of cylinder size and is calculated from the in-cylinder pressure $p$ using the following formula:

$$
\operatorname{IMEP}=\frac{1}{V_{S}} \oint p d V
$$

where $V_{S}$ is the swept volume of the cylinder.

However, different IMEP values can be distinguished in 4-

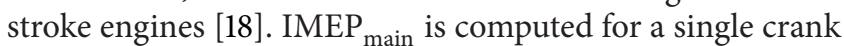
revolution including compression, combustion, and expansion. IMEP $_{\text {exch }}$ expresses the indicated work of the gas exchange processes, including NVO. $\mathrm{IMEP}_{\text {net }}$, which relates to the whole engine cycle, is the sum of the two aforementioned values.

Combustion evolution was analyzed using net heat release $q$ traces, computed on the basis of the first law of thermodynamics in the following form:

$$
q=\frac{\gamma}{\gamma-1} p d V+\frac{1}{\gamma-1} V d p
$$

where the ratio of specific heats $\gamma$ was calculated according to the instantaneous temperature and mixture composition in the cylinder.

The metrics representing the combustion timing were expressed as crank angle at the characteristic percentage values of standardized cumulative heat release, which is conventionally equated with the mass fraction burned (MFB) of fuel. The definitions of combustion evolution parameters are given in Figure 4.

Air-fuel ratio is defined as the ratio of the mass of aspirated air to the mass of injected fuel, and the excess air ratio $\lambda$ is expressed as the air-fuel ratio related to the stoichiometric air demand of the fuel. The mean $\lambda$ value was estimated on the basis of oxygen content in the exhaust gas measured with the use of a wide-band oxygen probe, while the cycle resolved $\lambda$ was computed using the gas flow model. The EGR rate was calculated as the ratio of trapped residuals to the entire in-cylinder load, including fuel, based on mass.

\section{Overall Experimental Results}

The average in-cylinder parameters are established in order to show how variable $\lambda$ influences mixture composition and combustion parameters. The main in-cylinder parameters at 3 investigated cases selected for the present experiments are shown in Table 2 . It should be noted that the $\lambda$ effect on the engine load was more complex than the one resulting solely from the excess air ratio due to the impact of the variable EGR rate. For leaner mixtures, lower exhaust temperatures were 


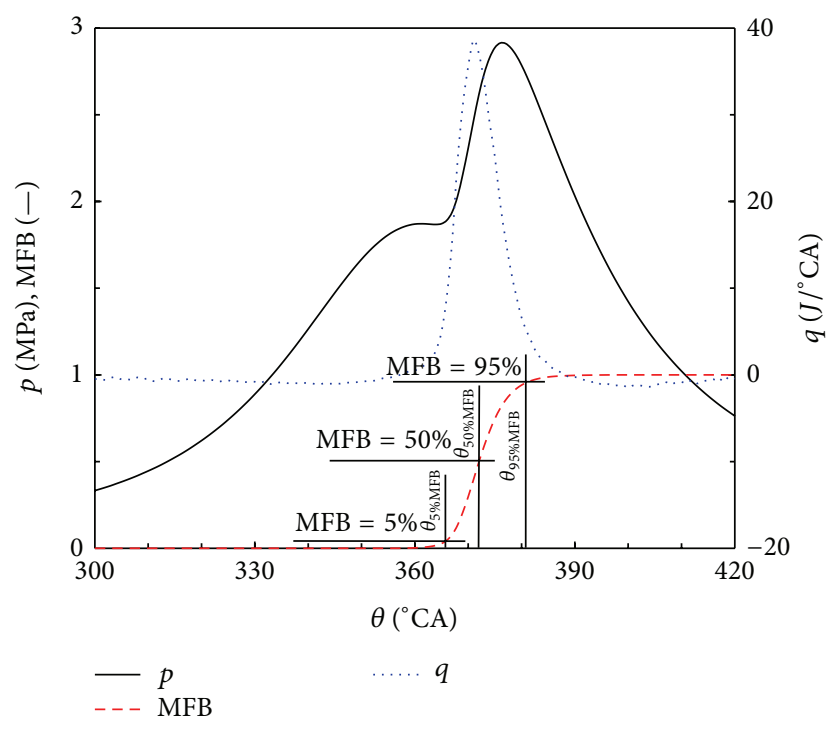

FIGURE 4: Definitions of combustion parameters and symbols.

TABLE 2: Overall in-cylinder parameters.

\begin{tabular}{|c|c|c|c|}
\hline Parameter & Case 1 & Case 2 & Case 3 \\
\hline$\lambda(-)$ & 1.034 & 1.097 & 1.188 \\
\hline$m_{F}(\mathrm{mg})$ & 15.02 & 11.78 & 9.60 \\
\hline$m_{A}(\mathrm{mg})$ & 228.7 & 190.1 & 167.8 \\
\hline$m_{\mathrm{exh}}(\mathrm{mg})$ & 152.4 & 181.7 & 205.6 \\
\hline $\mathrm{CoV}\left(m_{F}\right)(\%)$ & 0.24 & 0.35 & 0.52 \\
\hline $\mathrm{CoV}\left(m_{A}\right)(\%)$ & 2.04 & 1.66 & 2.63 \\
\hline $\operatorname{CoV}\left(m_{\mathrm{exh}}\right)(\%)$ & 7.99 & 7.22 & 7.48 \\
\hline EGR (\%) & 38.5 & 47.4 & 53.7 \\
\hline $\mathrm{IMEP}_{\text {net }}(\mathrm{MPa})$ & 0.346 & 0.278 & 0.215 \\
\hline $\operatorname{IMEP}_{\text {exch }}(\mathrm{MPa})$ & -0.052 & -0.042 & -0.025 \\
\hline $\mathrm{IMEP}_{\text {main }}(\mathrm{MPa})$ & 0.398 & 0.32 & 0.24 \\
\hline $\mathrm{CoV}\left(\mathrm{IMEP}_{\text {net }}\right)(\%)$ & 3.93 & 3.53 & 4.01 \\
\hline$\theta_{5 \% \mathrm{MFB}}\left({ }^{\circ} \mathrm{CA}\right)$ & 367.8 & 364.9 & 359.3 \\
\hline$\theta_{50 \% \mathrm{MFB}}\left({ }^{\circ} \mathrm{CA}\right)$ & 372.3 & 369.2 & 362.9 \\
\hline$\theta_{95 \% \mathrm{MFB}}\left({ }^{\circ} \mathrm{CA}\right)$ & 377 & 374.1 & 367.1 \\
\hline$\sigma\left(\theta_{50 \% \mathrm{MFB}}\right)\left({ }^{\circ} \mathrm{CA}\right)$ & 3.91 & 3.05 & 2.42 \\
\hline
\end{tabular}

observed that led to a higher exhaust density. The natural consequence of the above was an increase in the quantity of retained residuals $m_{\text {exh }}$ and the EGR rate. More exhaust in the cylinder during the intake process reduced the amount of aspirated air and the mass of fuel at a set $\lambda$ value. Thus, the $\lambda$ sweep was actually an EGR sweep.

It can be seen from Table 2 that the gas exchange work input (expressed as IMEP ${ }_{\text {exch }}$ ) is reduced for leaner mixtures, which can be attributed to NVO heat release. With leaner mixture, more oxygen was available during NVO which was, in turn, utilized for fuel oxidation.

Coefficients of variation $(\mathrm{CoV})$ in quantities of incylinder compounds (i.e., air, exhaust, and fuel), shown in Table 2, indicate that the amounts of trapped residuals are

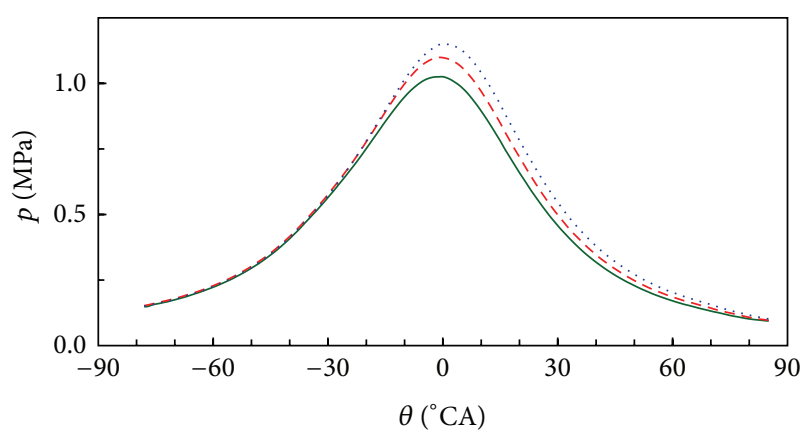

(a)

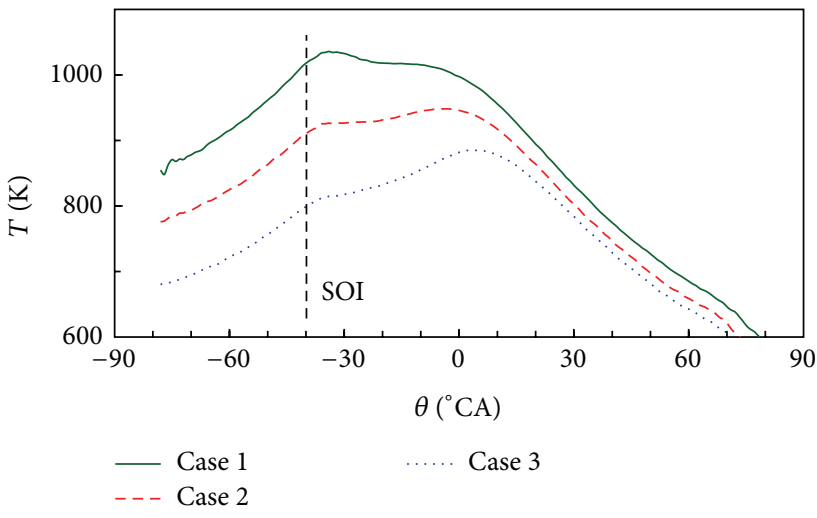

(b)

Figure 5: In-cylinder pressure (a) and temperature (b) during the NVO period.

the most variable, while the mass of fuel and mass of air are almost constant. Also, the CoV in IMEP ${ }_{\text {net }}$, under the investigated conditions, was kept below $5 \%$, which is commonly recognized as the acceptable level of combustion roughness [2].

The combustion timing characteristic values shown in Table 2 reveal that, with leaner mixture, earlier the autoignition occurred. Also, the combustion duration (distance between $5 \%$ and $95 \%$ of MFB) is shorter for lean mixtures. The standard deviation of 50\% MFB decreases with increasing $\lambda$. It primarily results from the earlier autoignition itself, as the increase in temperature during compression is more rapid at the moment of autoignition.

In order to provide more insight into the NVO thermal phenomena, the in-cylinder pressure and temperature traces during the NVO period are presented in Figure 5. In all three cases the start of recompression pressure was the same (Figure 5(a)); however, after fuel injection, higher pressures occurred with leaner mixtures. This observation can be attributed to heat release during the NVO period. The thermal effects of NVO injection are clearly seen on the temperature curves shown in Figure 5(b). With leaner mixture, lowering the start of recompression temperature could be observed. This drop in the temperature was the result of the excess air ratio itself and the increase in overall fuel dilution due to the effect of $\lambda$ on the EGR rate. Additionally, if a certain 


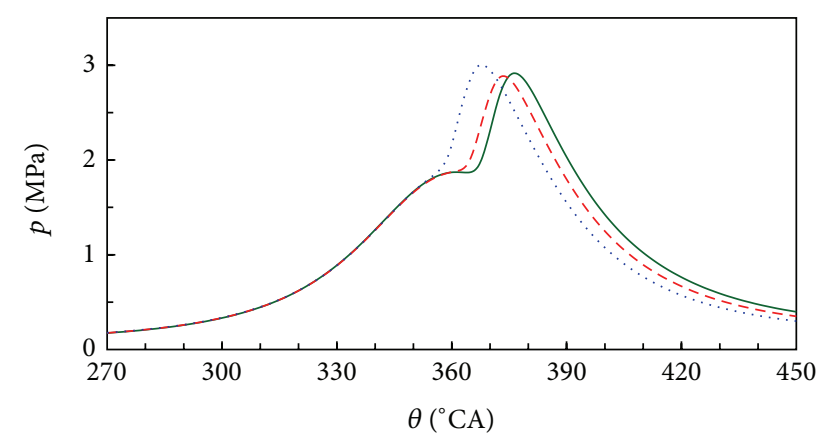

(a)

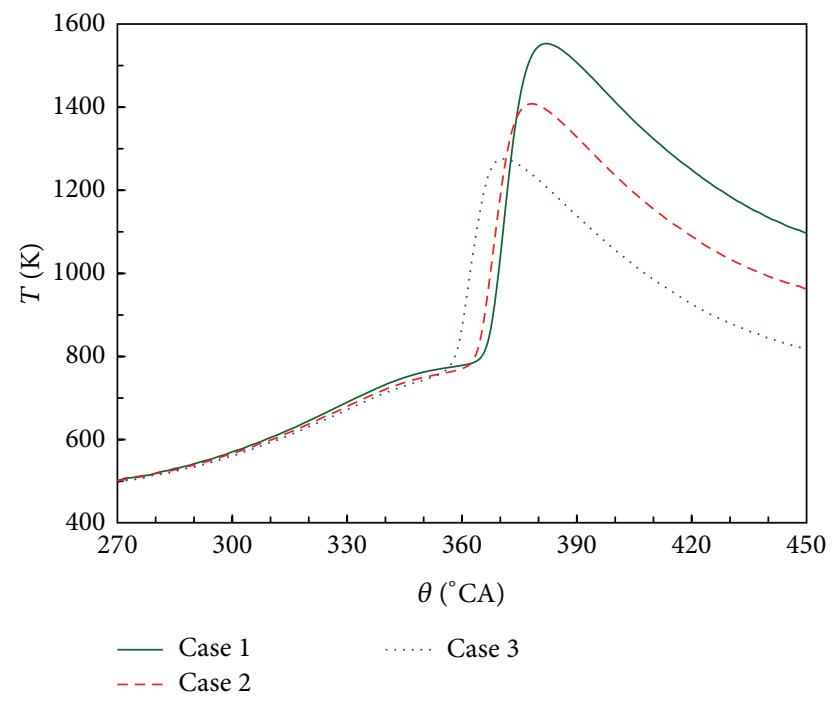

(b)

FIGURE 6: In-cylinder pressure (a) and temperature (b) during the main event.

amount of fuel chemical energy was consumed during the NVO period, less heat would be released during the main event, producing a lower end of combustion temperature. However, after fuel injection, the initial temperature difference was compensated to a considerable extent by heat release during the NVO period.

Figure 6 shows the in-cylinder pressure and temperature during the main event. It can be seen that the compression pressure histories are almost the same despite different mixture properties and different thermodynamic parameters after the main combustion. A careful analysis of Figure 6(b) indicates that differences at the end of compression temperatures result from the differences between adiabatic exponents. For lean mixtures, the higher EGR rate reduces the mixture adiabatic exponent, thus reducing the end of compression temperature. Besides the drop in temperature, the application of a leaner mixture resulted in the autoignition advance. This was due to the fact that oxygen availability enhances oxidative fuel reforming and increases the content of reforming products in the mixture. In other words, the autoignition temperature dropped with increasing the main event excess air.

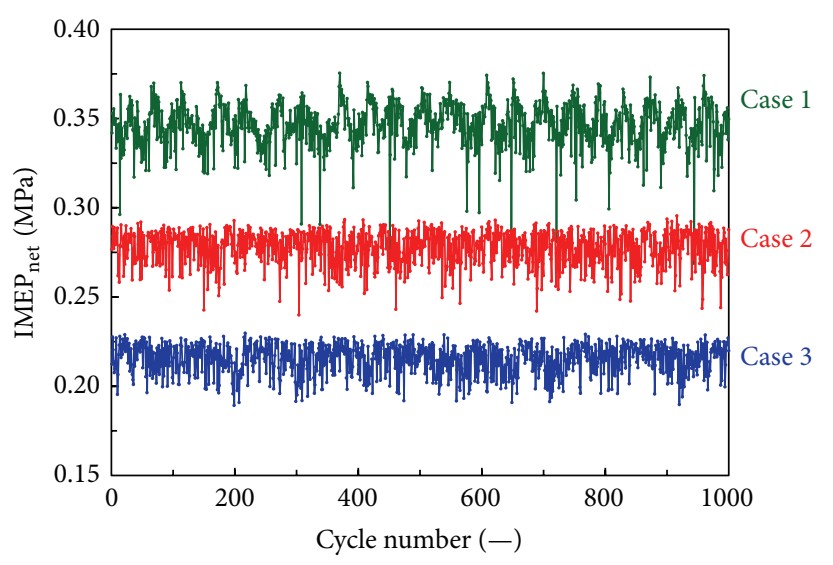

FIGURE 7: Net indicated mean effective pressure for 1000 consecutive cycles.

\section{Analysis of Cycle-by-Cycle Variability}

4.1. Correlations of Parameters. It is obvious that, during engine operation, even under steady conditions, the intake and exhaust processes are not perfectly identical in consecutive operating cycles. Therefore, cyclic variability in the excess air ratio and mass of trapped residuals is to be expected. The strong effect of mixture composition on the engine working cycle was shown in the previous section. It suggests that similar relationships can be observed from the cycle-by-cycle point of view. Under the NVO mode of operation, the amount of retained residuals is determined by mixture properties and the combustion process during the main event. However, the subsequent intake process, compression, and finally the next combustion are to a high extent controlled by the quantity and thermal conditions of the recirculated exhaust. These relationships create a feedback-loop between consecutive cycles. Fuel injection during the NVO period introduces an additional component to these effects, as the variable main event excess air ratio and the amount of trapped residuals control the extent of heat release during the NVO period.

The amounts of mechanical work produced by individual cycles, as demonstrated by the time series of $\mathrm{IMEP}_{\text {net }}$, are shown in Figure 7. Even without a thorough signal analysis it can be noted that the modes and amplitudes of variability in IMEP ${ }_{\text {net }}$ depend on mixture composition. For case 1 where stoichiometric mixture was created, $\mathrm{IMEP}_{\text {net }}$ exhibited slow oscillations, with a period of approximately 40 cycles. Similar waves were observed by Shahbakhti and Koch [22]. The said authors attributed this peculiar behavior to a coupling between pulsing supercharger flow and cylinder intake flow. However, in the current study, the engine was naturally aspirated. Furthermore, the measurements taken by Maurya and Agarwal [23] also demonstrated long period variations in IMEP under low load conditions. Thus, it is plausible that long period oscillations result from the in-cylinder processes themselves. Under close to stoichiometric conditions, long period oscillations in excess air can result in a variable degree of combustion completeness. It should be noted that such 


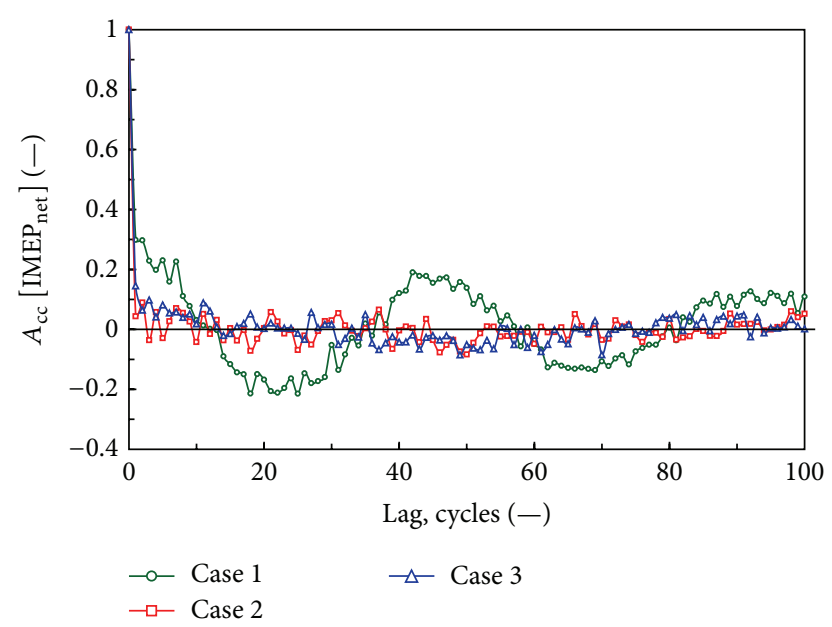

FIGURE 8: Autocorrelation of net indicated mean effective pressure.

variability in IMEP can lead to a long-period drift of the incylinder pressure transducer. Thus, to a certain extent, the observed waves can be magnified by artifacts from the pressure measurement path. Nevertheless, the primary reason for these oscillations must originate from the engine itself. When less fuel was injected and leaner mixtures were created (cases 2 and 3) while other conditions remained the same, these oscillations were not evident. To provide more insight into the periodic nature of work produced by consecutive engine cycles, autocorrelation functions are presented in Figure 8. Obviously, the autocorrelation function shows periodic changes in $\mathrm{IMEP}_{\text {net }}$ at stoichiometric mixture (case 1 ), with a period of approximately 47 cycles. For lean mixture (cases 2 and 3), the periodic component can be found as well, however, with a much smaller amplitude and twice as long period.

In order to identify sources of the cycle-by-cycle variability, the components of $\mathrm{IMEP}_{\text {net }}, \mathrm{IMEP}_{\text {main }}$, and IMEP $\mathrm{Ixch}_{\text {are }}$ presented in Figures 9 and 10. The graph heights were set to ensure a uniform scale on the vertical axes. It can be noted from Figure 9 that the amplitude in $\mathrm{IMEP}_{\text {main }}$ was much lower than in the case of IMEP $_{\text {net }}$. At the same time, Figure 10 indicates that long period oscillations are present in the gas exchange event as well as in the main event.

The correlations between $\mathrm{IMEP}_{\text {main }}$ and $\mathrm{IMEP}_{\text {exch }}$ are shown in Figure 11. The upper envelopes of the measurement points show a certain anticorrelation for lean mixtures (cases 2 and 3). This effect can be attributed to the consumption of a portion of fuel chemical energy during the NVO period. The heat release during NVO reduces the amount of energy available during the main event, thus reducing the indicated work. For stoichiometric mixtures, there is only a slight correlation between $\mathrm{IMEP}_{\text {main }}$ and $\mathrm{IMEP}_{\text {exch }}$, which means that there are different reasons for work production by NVO and the main event. In other words, this observation confirms that long period oscillations are engine related rather than measurement artifacts.

The correlations of combustion timing expressed by crank angle at $50 \% \mathrm{MFB}$ as a function of gas exchange IMEP

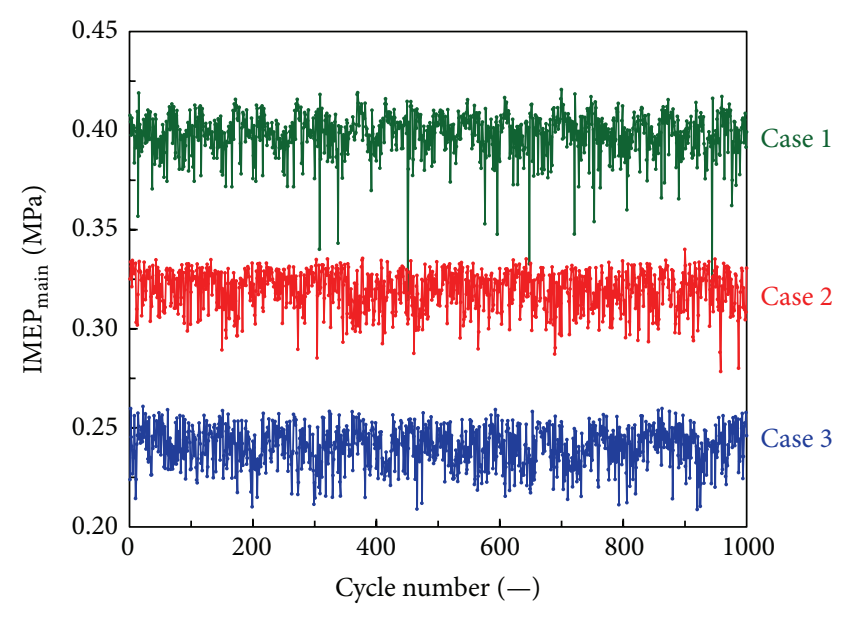

FIGURE 9: Main event IMEP for 1000 consecutive cycles.

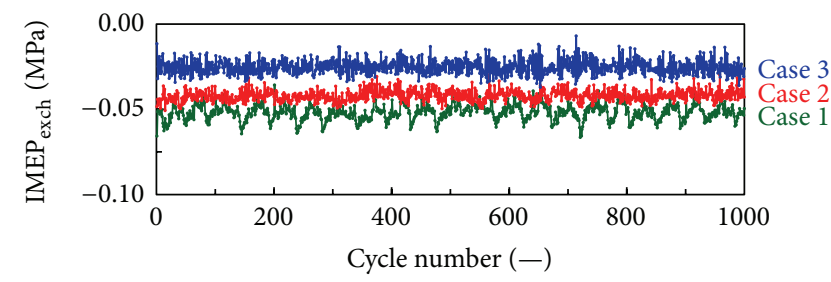

FIgURE 10: Gas exchange IMEP for 1000 consecutive cycles.

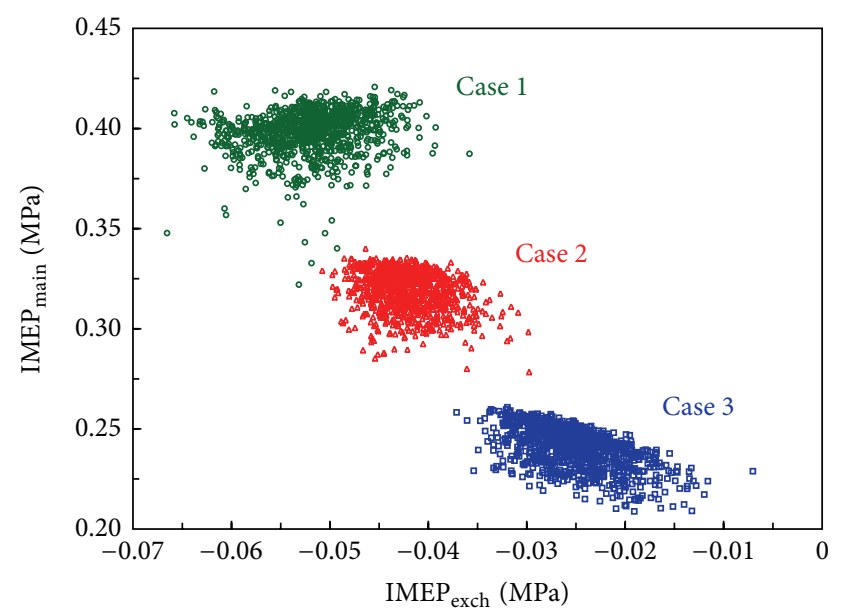

FIGURE 11: Correlations between main event IMEP and gas exchange IMEP for 1000 consecutive cycles.

are shown in Figure 12. It can be seen that for lean mixtures with higher $\mathrm{IMEP}_{\text {exch }}$ earlier combustion is observed. Moreover, fuel conversion into the main event work is affected by combustion timing. Both too early and too late combustion evolutions reduce the efficiency of fuel conversion into indicated work, which can be observed in Figure 13. For stoichio-

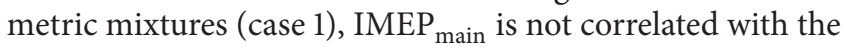
$\mathrm{IMEP}_{\text {exch }}$, as shown in Figure 11. However, a high variability in IMEP $_{\text {exch }}$ can be observed. Also, it can be seen from Figure 12 that the combustion timing is not affected by $\mathrm{IMEP}_{\text {exch. }}$. 


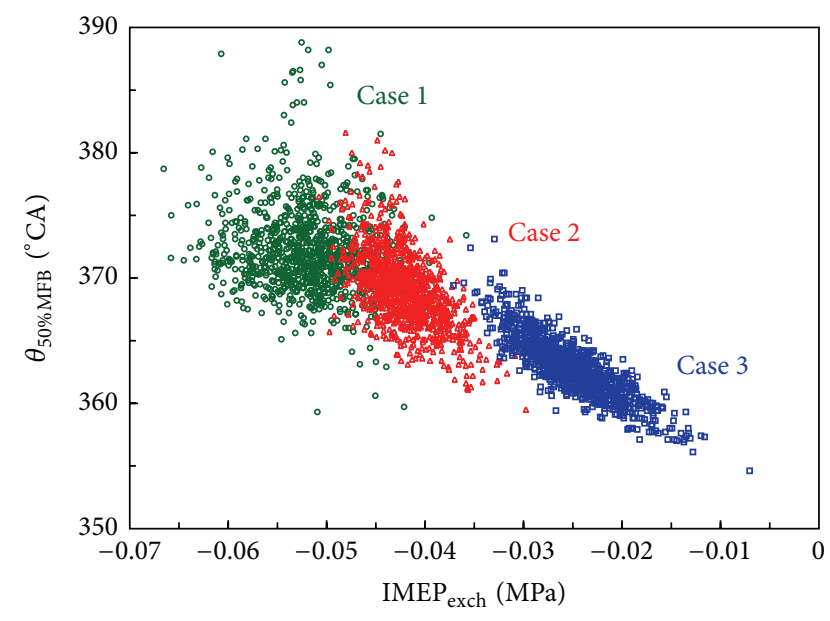

Figure 12: Correlations between gas exchange IMEP and crank angle at 50\% MFB for 1000 consecutive cycles.

4.2. Wavelet Analysis of Variability in IMEP. Wavelet analysis is a powerful tool for identifying the dominant modes of variability in a time series and the variations of these modes in time. This method has been successfully applied to detect combustion variability modes in spark ignition as well as diesel engines [24-26]. However, in these combustion systems there is only a weak feedback-loop between consecutive cycles, which originates from residuals or thermal effects. In the case of a residual effected HCCI engine, there is a much stronger coupling due to large amounts of internally recirculated exhaust. It was demonstrated by Sen et al. [10] that the HCCI heat release variability includes long period small amplitude oscillations as well as intermittent high frequency oscillation events. However, the mentioned research was performed for an engine with a port fuel injection. It is expected that exhaust-fuel interactions during the NVO period would introduce additional components to the modes of cycle-by-cycle variability.

In the present analyses, a complex Morlet wavelet of order 6 was used as the mother wavelet. This type of wavelet guarantees identification of short-range wave propagation; thus, it enables detection of typical trends appearing in cycleby-cycle variations. This approach was used in a number of previous studies [24-26]. With the use of a continuous wavelet transform, the power spectra of the analyzed data series were calculated according to the procedure presented in [27]. The results of these calculations are presented in Figure 14.

It can be noted from Figure 14(a) that the analyzed $\mathrm{IMEP}_{\text {net }}$ series include a periodic stationary component with a period ranging between 30 and 50 cycles. In case 2, this component appears temporarily at cycles 170 and 85 . At the same time, a more stationary band of about 120 cycles persisted between cycles 100 and 700. For the leanest mixture (case 3), the 30-cycle long band disappeared. Apart from slow changes, short-period large-amplitude repetitive events can be noted in all analyzed cases.

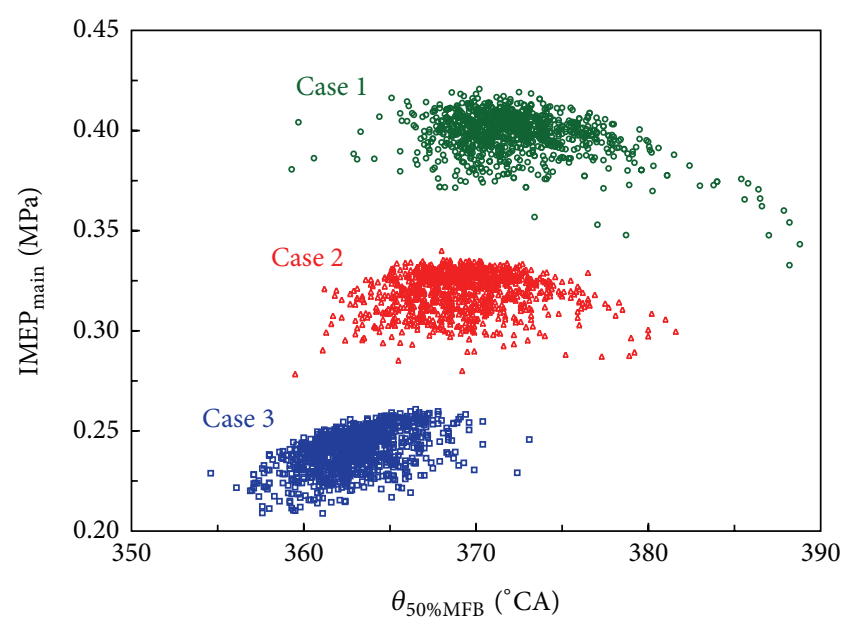

FIGURE 13: Correlations between crank angle at 50\% MFB and main event indicated mean effective pressure for 1000 consecutive cycles.

4.3. Recognition of Patterns in IMEP. In order to identify short-period and large-amplitude deterministic patterns in $\mathrm{IMEP}_{\text {net }}$, an in-house algorithm was applied. The algorithm searched for the most representative patterns in the data series of IMEP $_{\text {net }}$ as a vector of parameters that are most frequently repeated in the analyzed data series. The data series of IMEP ${ }_{\text {net }}$ were standardized, giving a vector of input data $X$, which included $N$ values for consecutive cycles. In the present case $N=1000$. For each length $n$ of the searched pattern, the values of matrix $Y_{j, k}$ were computed using the following formula:

$$
Y_{j, k}(n)=\frac{1}{n} \sum_{i=1}^{n}\left(X_{j+i-1} \cdot X_{k+i-1}\right),
$$

where $j \in\langle 1, N-n\rangle$ and $k \in\langle 1, N-n\rangle$. Afterwards, the obtained correlations for each of the analyzed patterns were standardized for all fittings across all input vector data samples:

$$
W_{j}(n)=\frac{1}{N-n} \sum_{k=1}^{N-n} Y_{j, k}
$$

However, negative values were omitted (replaced with zeroes) in the calculation procedure. The pattern with the best fit was identified as the vector of data starting from the index $j$ and with the length $n$ indicating the peak value of variable $W_{j}$. The peak values of the variable $W_{j}$ with respect to the length of the pattern vector $n$ are shown in Figure 15.

Short period patterns in IMEP were represented by vectors of 16 samples in length. These patterns for 8 most representative recognized series under stoichiometric (case 1) and lean (case 2) conditions are shown in Figure 16. In the stoichiometric mixture case (Figure 16(a)), the most representative pattern in $\mathrm{IMEP}_{\text {net }}$ shows that, after a number of stable operation cycles, an accidental drop in $\mathrm{IMEP}_{\text {net }}$ appears (cycle 7). However, a slight gradual increase in IMEP ${ }_{\text {net }}$ can be observed before this event. This cycle is followed by a cycle 


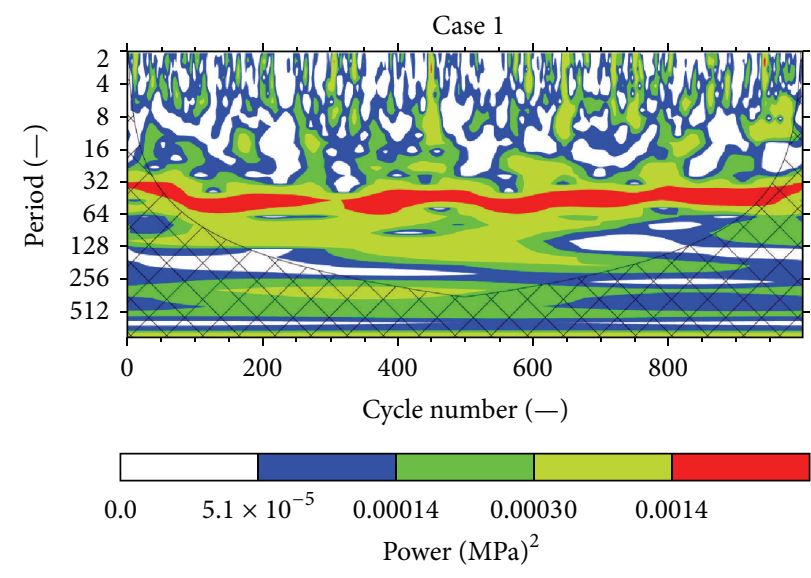

(a)

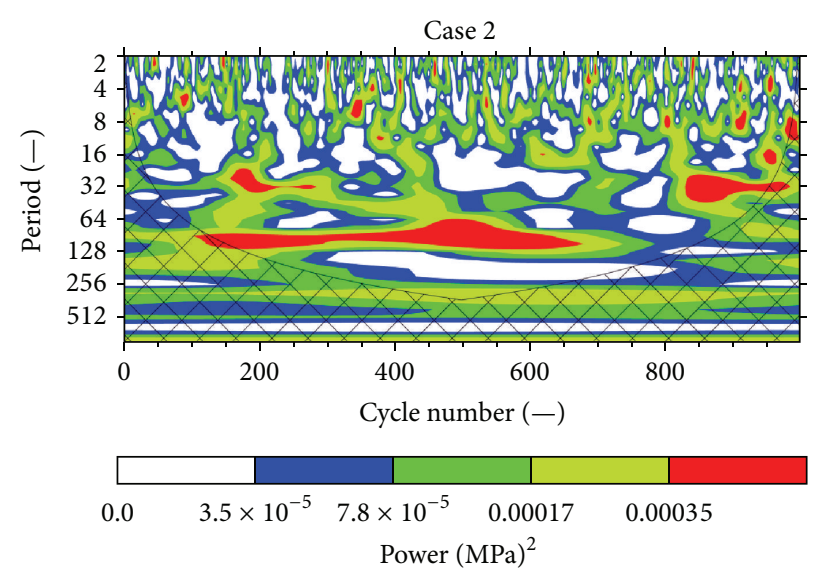

(b)

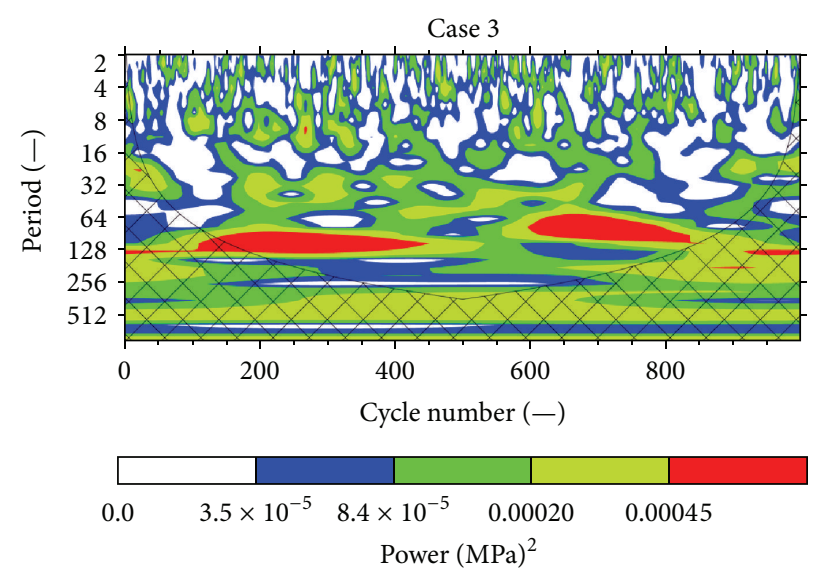

(c)

FIGURE 14: Wavelet power spectra of the net IMEP. The contour levels are chosen such that 75\%, 50\%, 25\%, and 5\% of the wavelet power are above each level, respectively. The cross-hatched region represents the cone of influence, where zero padding has reduced the variance.

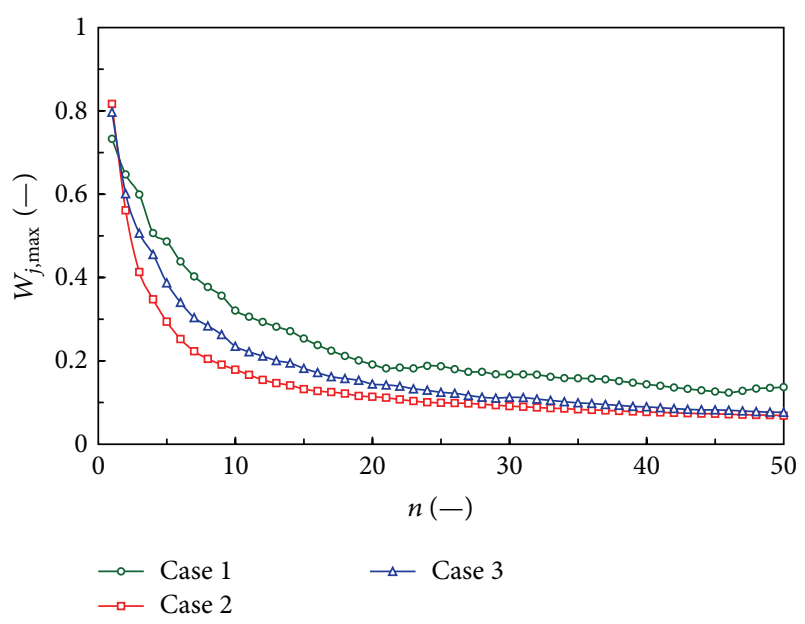

FIGURE 15: Parameter $W_{j, \max }$ versus the length of pattern $n$.

with relatively high indicated work and a few oscillating cycles. Afterwards, another gradual increase in $\mathrm{IMEP}_{\text {net }}$ was observed, starting from cycle 13. In the lean mixture regime (case 3), the identified patterns did not include high amplitude disturbances, as was observed under stoichiometric conditions. Figure 16(b) shows the alternating high and low values of IMEP ${ }_{\text {net }}$ followed by the 3-state distinctive patterns, starting from cycle 7. However, after a few cycles, the variability pattern returns to the alternative style. These patterns indicate that the variability in excess air in the consecutive cycles result in variable amounts of work produced by the NVO period and the main event.

\section{Conclusions}

A gasoline HCCI engine with a fully variable valvetrain and direct gasoline injection was used for the analysis of cycle-bycycle variability. The engine was operated in the NVO mode and fuel was injected directly into the cylinder during exhaust recompression. The findings of this study can be summarized as follows.

(1) Under stoichiometric conditions 47-cycle long periodical fluctuations in IMEP were identified. The reason for these changes is not clear; however, it is plausible that they result from changes in the excess 


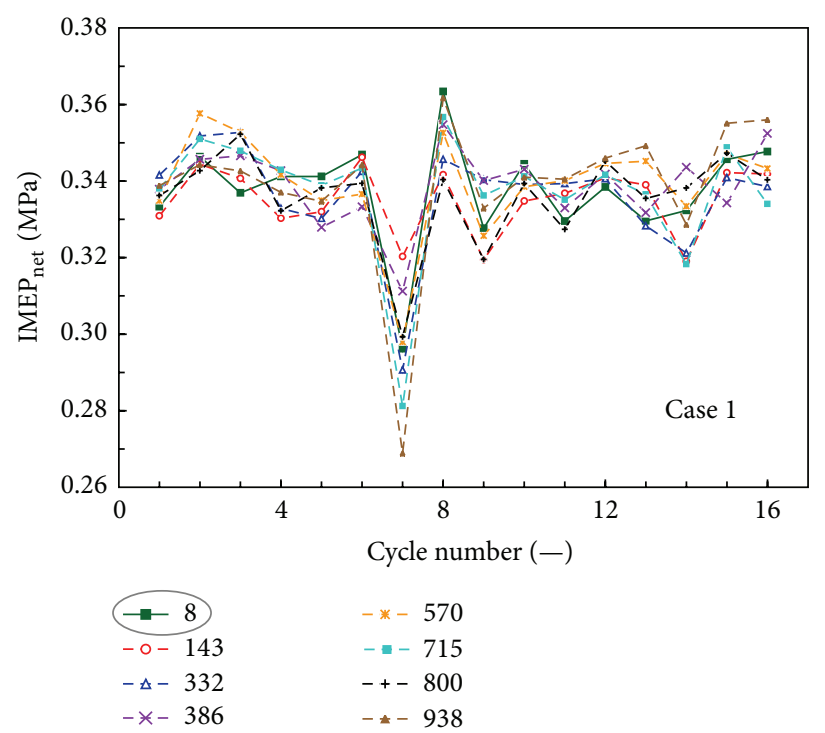

(a)

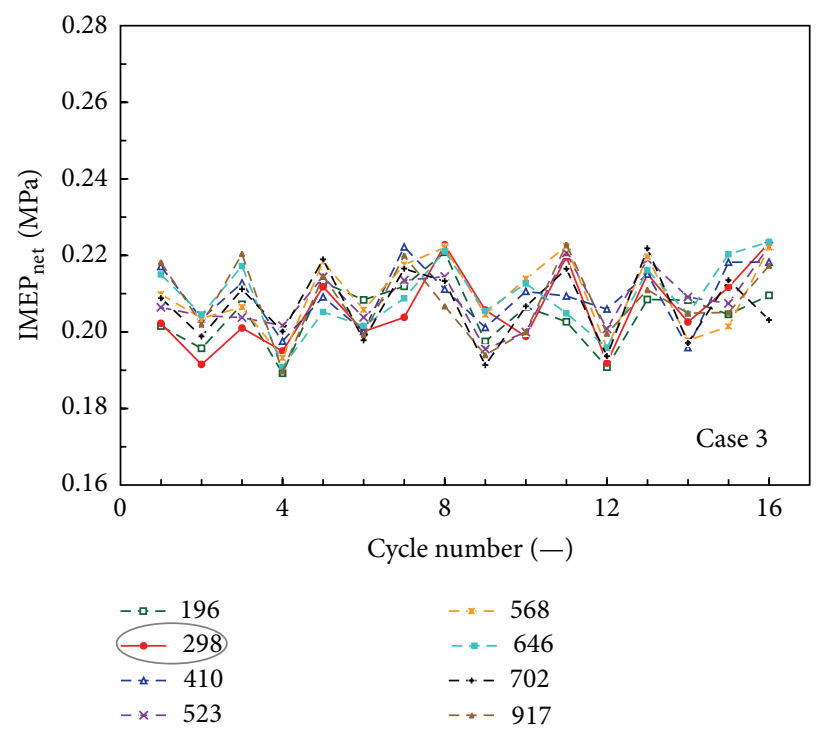

(b)

Figure 16: Patterns of representative cycles in terms of IMEP $_{\text {net }}$. The numbers reveal cycles in the data series, as seen in Figure 7, which commence with each pattern. The most representative patterns for each case are plotted with solid lines.

air ratio, which, in turn, controls amounts of fuel chemical energy released in a given cycle. In contrast, these oscillations disappeared for reduced amounts of fuel under the average lean mixture regime. In this case, the variations in excess air did not result in rich mixture cycles and, consequently, the amounts of released heat were controlled solely by the quantity of fuel.

(2) The correlations between the main event IMEP and the gas exchange IMEP reveal that under the lean mixture regime heat release during the NVO period reduces the work produced by the subsequent main event combustion. Also, the NVO heat release increased the temperature at the end of exhaust expansion. This process increased the main event compression temperature and, as a result, advanced autoignition. However, such relationships were not observed for stoichiometric mixture.

(3) The application of continuous wavelet transforms revealed that the time series in IMEP contained long period quasistationary components, with the period dependent on excess air. Also, short-period, largeamplitude repetitive events were observed in all investigated cases.

(4) The identified repetitive patterns in IMEP showed different mechanisms of such variability for different air-excess ratios and the resulting dominant processes during the NVO period. Under stoichiometric mixture, all patterns are characterized by the occurrence of an accidental low IMEP cycle preceded by a few quasistable cycles. Under the lean mixture regime, the variability in IMEP is dominated by 2 -state and 3 -state variations.

\section{Conflict of Interests}

The author declares that there is no conflict of interests regarding the publication of this paper.

\section{Acknowledgment}

The research was financed by the Polish National Science Center under Grant no. 2012/05/B/ST8/00077.

\section{References}

[1] J. B. Roberts, J. C. P. Jones, and K. J. Landsborough, "Stochastic modelling and estimation for cyclic pressure variations in spark ignition engines," Mechanical Systems and Signal Processing, vol. 15, no. 2, pp. 419-438, 2001.

[2] M. Ozdor, M. Dulger, and E. Sher, "Cyclic variability in spark ignition engines. A literature survey," SAE Technical Paper 940987, SAE, 1994.

[3] P. L. Curto-Risso, A. Medina, A. Calvo Hernández, L. GuzmánVargas, and F. Angulo-Brown, "On cycle-to-cycle heat release variations in a simulated spark ignition heat engine," Applied Energy, vol. 88, no. 5, pp. 1557-1567, 2011.

[4] J. Czarnigowski, P. Jakliński, and M. Wendeker, "Fuelling of aircraft radial piston engines by ES95 and 100LL gasoline," Fuel, vol. 89, no. 11, pp. 3568-3578, 2010.

[5] M. Yao, Z. Zheng, and H. Liu, "Progress and recent trends in homogeneous charge compression ignition (HCCI) engines," Progress in Energy and Combustion Science, vol. 35, no. 5, pp. 398-437, 2009.

[6] M. Izadi Najafabadi and N. Abdul Aziz, "Homogeneous charge compression ignition combustion: challenges and proposed solutions," Journal of Combustion, vol. 2013, Article ID 783789, 14 pages, 2013. 
[7] J. Lavy, J. Ch. Dabadie, Ch. Angelberger et al., "Innovative ultra-low $\mathrm{NO}_{X}$ controlled auto-ignition combustion process for gasoline engines: the 4-SPACE project," SAE Technical Paper 2000-01-1837, 2000.

[8] H. Zhao, J. Li, T. Ma, and N. Ladommatos, "Performance and analysis of a 4-stroke multi-cylinder gasoline engine with CAI combustion," SAE Technical Paper 2002-01-0420, 2002.

[9] L. Koopmans, O. Backlund, and I. Denbratt, "Cycle to cycle variations: their influence on cycle resolved gas temperature and unburned hydrocarbons from a camless gasoline compression ignition engine," SAE Technical Paper 2002-01-0110, SAE, 2002.

[10] A. K. Sen, G. Litak, K. D. Edwards, C. E. A. Finney, C. S. Daw, and R. M. Wagner, "Characteristics of cyclic heat release variability in the transition from spark ignition to HCCI in a gasoline engine," Applied Energy, vol. 88, no. 5, pp. 1649-1655, 2011.

[11] E. Hellström, A. Stefanopoulou, J. Vavra et al., "Understanding the dynamic evolution of cyclic variability at the operating limits of HCCI engines with negative valve overlap," SAE International Journal of Engines, vol. 5, no. 3, pp. 995-1008, 2012.

[12] M. K. Lalith, A. Dinesh, S. Unnikrishnan, A. Radhakrishnan, S. Srihari, and V. R. Kishore, "Modeling of homogeneous mixture formation and combustion in GDI engine with negative valve overlap," ISRN Mechanical Engineering, vol. 2013, Article ID 521375, 12 pages, 2013.

[13] J. Hunicz, "An experimental study of negative valve overlap injection effects and their impact on combustion in a gasoline HCCI engine," Fuel, vol. 117, pp. 236-250, 2014.

[14] J. Hunicz, M. Geca, A. Rysak, G. Litak, and P. Kordos, "Combustion timing variability in a light boosted controlled autoignition engine with direct fuel injection," Journal of Vibroengineering, vol. 15, no. 3, pp. 1004-1012, 2013.

[15] R. M. Wagner, K. D. Edwards, C. S. Daw, J. B. Green, and B. G. Bunting, "On the nature of cyclic dispersion in spark assisted HCCI combustion,” SAE Technical Paper 2006-01-0418, 2006.

[16] C. S. Daw, R. M. Wagner, K. D. Edwards, and J. B. Green Jr., "Understanding the transition between conventional sparkignited combustion and HCCI in argasoline engine," Proceedings of the Combustion Institute, vol. 31, pp. 2887-2894, 2007.

[17] A. Ghazimirsaied and C. R. Koch, "Controlling cyclic combustion timing variations using a symbol-statistics predictive approach in an HCCI engine," Applied Energy, vol. 92, pp. 133146, 2012.

[18] J. B. Heywood, Internal Combustion Engine Fundamentals, McGraw-Hill Book Company, New York, NY, USA, 1988.

[19] G. M. Shaver, M. J. Roelle, and J. C. Gerdes, "Modeling cycleto-cycle dynamics and mode transition in HCCI engines with variable valve actuation," Control Engineering Practice, vol. 14, no. 3, pp. 213-222, 2006.

[20] F. Sun, X. Chen, D. S.-K. Ting, and A. Sobiesiak, "Modeling operation of HCCI engines fueled with ethanol," in Proceedings of the American Control Conference (ACC '05), pp. 1003-1009, Portland, Ore, USA, June 2005.

[21] K. Brzozowski and J. Nowakowski, "Model for calculating compression ignition engine performance," Eksploatacja i Niezawodnosc-Maintenance and Reliability, vol. 16, no. 3, pp. 407414, 2014

[22] M. Shahbakhti and C. R. Koch, "Characterizing the cyclic variability of ignition timing in a homogeneous charge compression ignition engine fuelled with n-heptane/iso-octane blend fuels," International Journal of Engine Research, vol. 9, no. 5, pp. 361397, 2008.
[23] R. K. Maurya and A. K. Agarwal, "Experimental investigation of cyclic variations in HCCI combustion parameters for gasoline like fuels using statistical methods," Applied Energy, vol. 111, pp. 310-323, 2013.

[24] A. K. Sen, G. Litak, R. Taccani, and R. Radu, "Wavelet analysis of cycle-to-cycle pressure variations in an internal combustion engine," Chaos, Solitons and Fractals, vol. 38, no. 3, pp. 886-893, 2008.

[25] A. K. Sen, R. Longwic, G. Litak, and K. Górski, "Analysis of cycle-to-cycle pressure oscillations in a diesel engine," Mechanical Systems and Signal Processing, vol. 22, no. 2, pp. 362-373, 2008.

[26] A. K. Sen, G. Litak, C. E. A. Finney, C. S. Daw, and R. M. Wagner, "Analysis of heat release dynamics in an internal combustion engine using multifractals and wavelets," Applied Energy, vol. 87, no. 5, pp. 1736-1743, 2010.

[27] C. Torrence and G. P. Compo, "A practical guide to wavelet analysis," Bulletin of the American Meteorological Society, vol. 79, no. 1, pp. 61-78, 1998. 


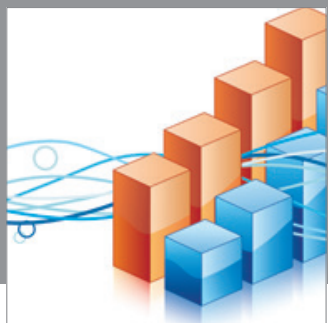

Advances in

Operations Research

mansans

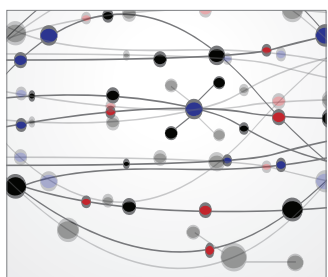

The Scientific World Journal
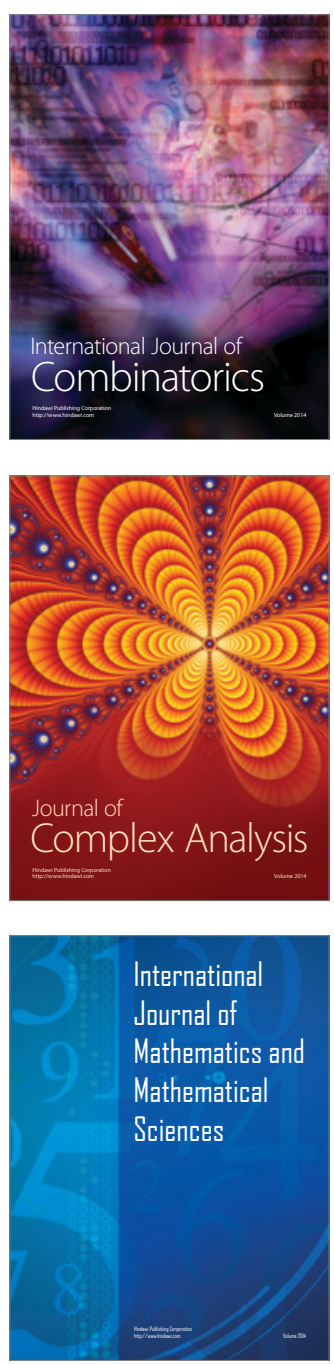
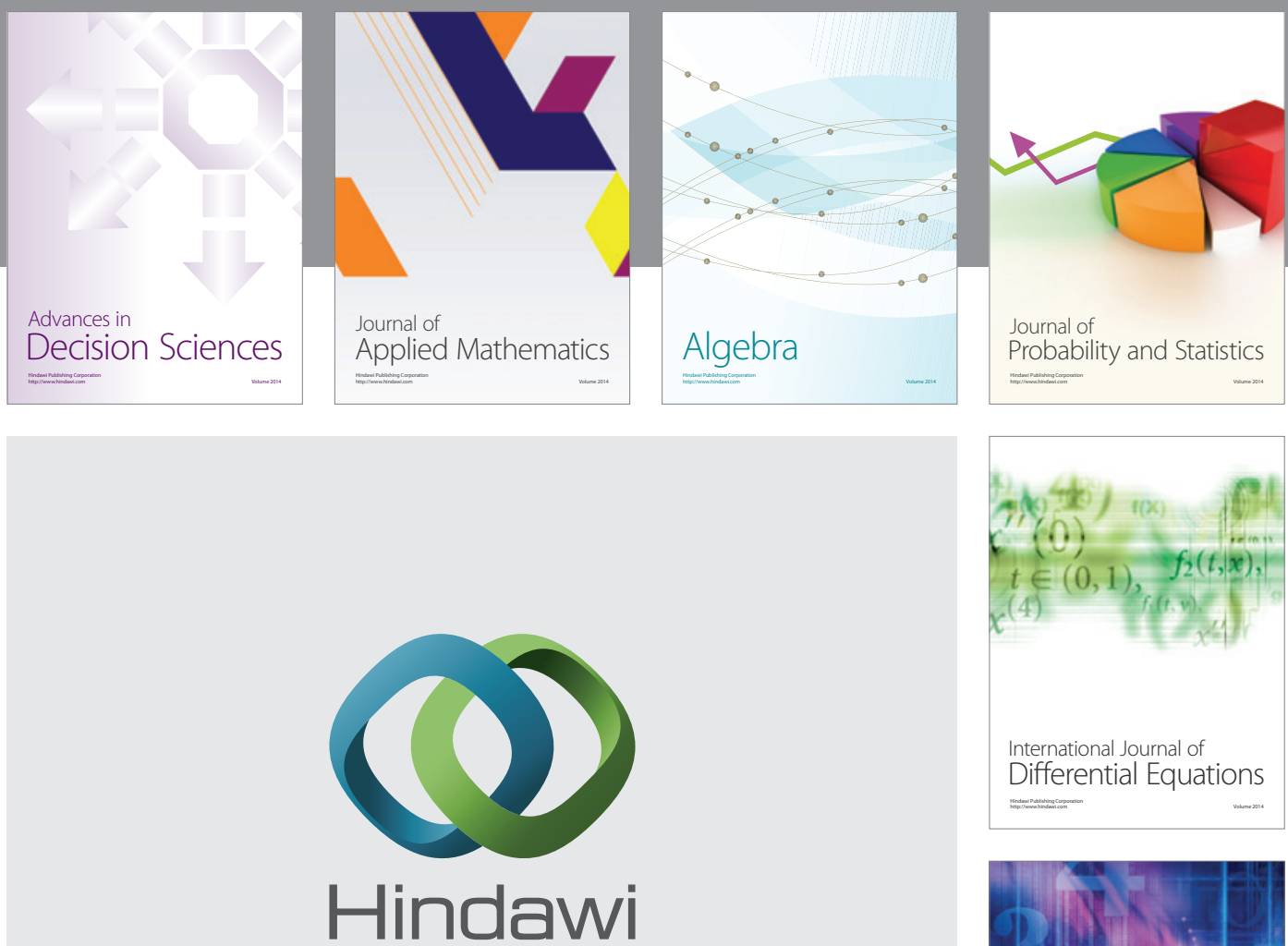

Submit your manuscripts at http://www.hindawi.com
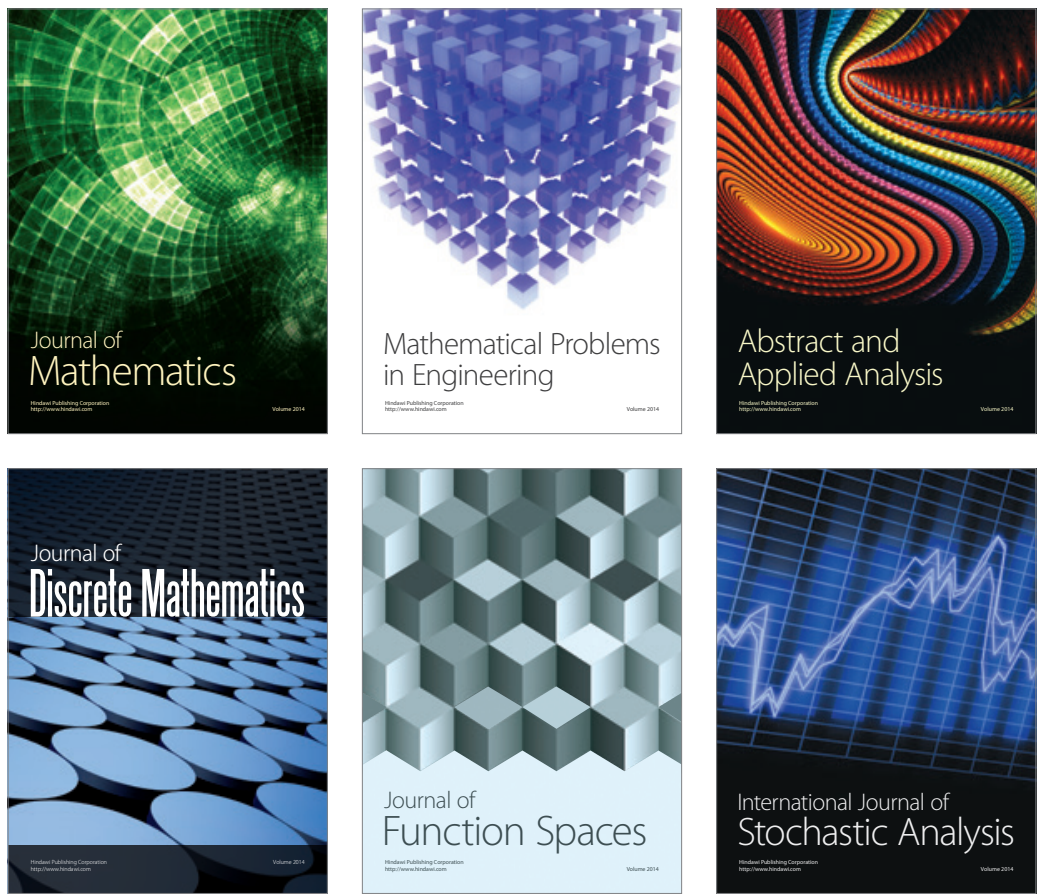

Journal of

Function Spaces

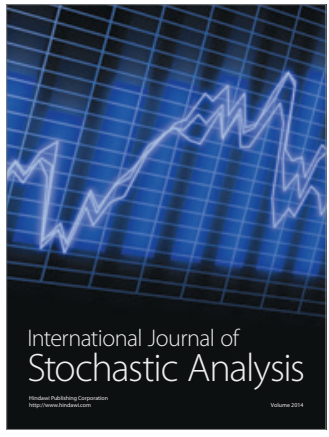

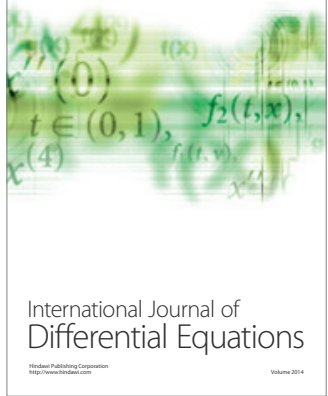
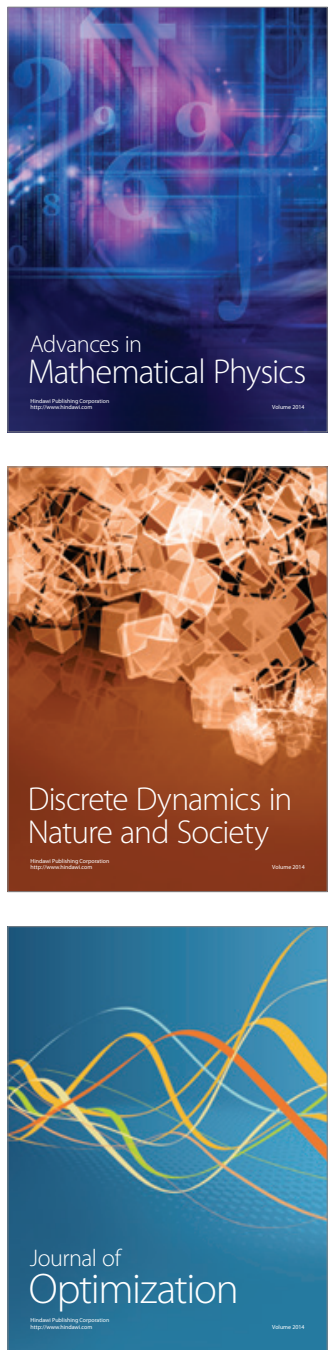